\title{
Role of Infection in Post-Tonsillectomy Secondary Hemorrhage - An Experience at King Abdulaziz University Hospital, Riyadh, Saudi Arabia
}

\author{
Alkarzae M*, AlSanosi A, Alharbi M, Altamimi F, Alzendi N \\ King Abdulaziz University Hospital, Saudi Arabia
}

Submission: March 22, 2016; Published: March 28, 2017

*Corresponding author: Mohammed A. Alkarzae, Department of Otorhinolaryngology - Head and Neck Surgery, Security Forces Hospital, Riyadh, Saudi Arabia, Email: M.alkarzae@hotmail.com

\begin{abstract}
Introduction: Tonsillectomy is one of the most common otolaryngology procedures and main complications of tonsillectomy are postoperative hemorrhage, infection and pain. Hemorrhage can be divided into two broad categories; primary, occurring $<24 \mathrm{~h}$ after surgery and secondary, occurring $>24 \mathrm{~h}$ post operation and it has a reported rate of $3-5 \%$.

Objectives: The present study was conducted to ascertain the causes of secondary post tonsillectomy hemorrhage and to confirm whether infection acts as a cause of such hemorrhage or not.

Methods: It was a retrospective study conducted at the department of Otolaryngology (ENT), King Abdulaziz University Hospital (KAUH), Riyadh, Kingdom of Saudi Arabia. The study was conducted from 2012-2013. A total of 53 patients undergoing tonsillectomy were included in the study. Pre-and post-operative leukocyte counts, use of antibiotics and occurrence of secondary hemorrhage were cross-tabulated and analysed with the help of Fisher exact test to measure strength of association.

Results: The number of cases reported during the study period with post-tonsillectomy secondary bleeding was 47 (88.7\%). The mean age of the patients reporting with secondary hemorrhage was 14.1 years (range: $2-45$ ). The mean number of days post-operatively after which the bleeding started was 6.7 days (range: 0 - 18). In current study, $11(20.8 \%)$ patients had WBC count above 11,000 per cubic millimeter postoperatively. Six out of these 11 cases showed neutrophils to be more than $70 \%$. When the observation of secondary hemorrhage was crosstabulated against the post-operative raise WBCs (infections) and intra-operative antibiotics used, it was found to have no significance ( $p=0.957$ and 0.210 respectively).
\end{abstract}

Conclusion: Current study concludes that infection is not a significant cause of post-tonsillectomy secondary hemorrhage and use of antibiotics has no role in reduction of such hemorrhage.

Keywords: Tonsillectomy; Secondary Hemorrhage; Infection; Antibiotics

\section{Introduction}

Tonsillectomy is one of the commonest otolaryngology procedures performed, representing $\sim 20 \%$ of surgical procedures performed in this field [1]. The main complications of tonsillectomy are post-operative hemorrhage, infection and pain. Hemorrhage has been divided into two broad categories; primary, occurring $<24 \mathrm{~h}$ after surgery and secondary, occurring $>24$ h post operation although commonly 5- 10 days after the operation [1-4]. Post-tonsillectomy secondary hemorrhage has a reported rate of $3-5 \%$ leading to re-admission to hospital $[5,6]$. Infection has been thought as a cause of post-tonsillectomy secondary hemorrhage without evidence to support this. [1$3,5,7]$. In fact, some studies have showed that there is no effect on the complication rate with usage of prophylactic antibiotics
$[1,7]$. Irrespective of this the traditional treatment of posttonsillectomy secondary hemorrhage has been empirical, involving readmission to hospital, antibiotics, analgesia and various mouthwashes.

Outcome measurements of post-tonsillectomy bleeding were given in the literature as early as $1948[8,9]$. Since then, definitions of primary and secondary bleeding have been well established in the literature however, incongruent descriptions of postoperative bleeding have been used, making the data in the literature hard to interpret and compare. What may be considered significant bleeding in one study may not be considered significant in another. Several authors have shown frustration with the range of bleeding rates in the literature 
$0.28 \%$ to $20 \%$ and have called for standardized protocols and consistency in reporting bleeding to allow for comparisons between medical centers and techniques. Differences in bleeding rates and descriptions of post-tonsillectomy bleeding make it difficult to accurately discuss tonsillectomy bleeding with patients and parents and, furthermore, make comparisons of various new and/or old techniques difficultto interpret and evaluate $[10,11]$.

Blakley [12] in their meta-analysis included 63 published studies on post-tonsillectomy hemorrhage and described a mean hemorrhage rate of $4.5 \%$ with a standard deviation of $9.4 \%$ and he mentioned that a maximum hemorrhage rate of $13.9 \%$ may be expected. One of the largest reports on posttonsillectomy hemorrhage was the prospective National Tonsil Audit in the United Kingdom by Lowe et al. [13] covering about 34,000 patients undergoing tonsillectomy which reported a postoperative hemorrhage rate of $3.5 \%$ covering bleeding that occurs during hospitalization and bleeding leading to readmission; $0.9 \%$ of all patients were returned to theatre. A retrospective study conducted by Windfuhr et al. [14] conducted on 15,218 patients in Germany found a return-to-theatre rate of $2.86 \%$ for tonsillectomy. The risk factors associated with post tonsillectomy hemorrhage range from type of surgery, the patients' age and sex, indication for surgery, operation technique, and abnormal coagulation tests to postoperative infection of the tonsillar fossa [15].

Ahsan et al. [16] showed that infection of the tonsillar fossa is not a significant risk factor for secondary hemorrhage [16] while another study described a positive relationship between preoperative bacterial colonization of the tonsillar fossa and postoperative hemorrhage, recommending antibiotics peri-operatively [17]. However, the use of antibiotics did not reduce the risk of post-tonsillectomy hemorrhage as shown by later investigators $[18,19]$. The present study was conducted to ascertain the causes of secondary post tonsillectomy hemorrhage leading to denial or confirmation of infection as a cause of hemorrhage. This will ultimately improve curative and preventive methods for management of hemorrhage.

\section{Methods}

\section{Study design and setting}

It was a retrospective study conducted at the department of Otolaryngology (ENT), King Abdulaziz University Hospital (KAUH), Riyadh, Kingdom of Saudi Arabia.

\section{Study duration}

The study was conducted for two years i.e. from 2012-2013.

\section{Study population}

All those patients who presented to the ENT department of KAUH with an indication of tonsillectomy and underwent this procedure at the same hospital and then developed secondary post tonsillectomy bleeding were included in the study after formal approval of the Institutional Ethics Review Board. Patients whose complete clinical data was not available to rule in or to rule out the infection as a cause of the bleeding were excluded from the study.

\section{Data Collection}

Complete clinical data including name, age, gender, medical record number, presenting symptoms, grade of tonsils, indication of tonsillectomy, surgical technique applied, surgeon's name, date of operation, intra-operative medications (Dexamethasone, Paracetamol), post-operative medications (Paracetamol, antibiotics, non-steroidal anti-inflammatory drugs), day of secondary bleeding and pre-operative and post-operative laboratory investigations performed mainly the total leukocyte count (TLC or WBC count), absolute count and percentage of neutrophils, lymphocytes, monocytes, eosinophils and basophils were recorded.

\section{Data analysis}

All data was entered and analysed with the help of Statistical Package for Social Sciences (SPSS) version 17.0. Quantitative variables like age, $\mathrm{WBC}$ count etc were presented as means $\pm \mathrm{SD}$ and qualitative variables like gender, use of antibiotics (yes, no) etc were presented as frequencies and percentages. Fisher exact test was used to measure the strength of association between qualitative variables. Any p-value less than 0.05 was considered statistically significant.

\section{Results}

The number of cases reported during the study period with post-tonsillectomy secondary bleeding was 47 . Out of these, 23 $(43.4 \%)$ were females and 30 (56.6\%) were males. The mean age of the patients reporting with secondary hemorrhage was 14.1 years (range: 2 - 45). The mean number of days post-operatively after which the bleeding started was 6.7 days (range: 0 - 18).

A greater number of tonsillectomies, i.e. 38 (71.7\%) cases were done by senior surgeons while 15 (28.3\%) cases were done by junior surgeons. Most of the cases in the study were operated for grade 3 tonsillitis which was 31 (58.5\%). 16 (30.2\%) patients were with grade 2 , and 3 cases each $(5.7 \%$ each) for grade 1 and grade 4 tonsillitis. Most of the cases, i.e. 39 patients $(73.6 \%)$ were operated for tonsillitis due to recurrent tonsillitis accompanied with airway obstruction, while 13 (24.5\%) were only due to recurrent tonsillitis and only 1 case $(1.9 \%)$ had airway obstruction as a sole indication for surgery. Bipolar surgical technique was used in 25 cases (47.2\%), cold technique in 19 patients $(35.8 \%)$ and monopolar technique was employed in 9 cases $(17 \%)$.

All patients were given dexamethasone and paracetamol intra-operatively. Paracetamol was also taken by all cases postoperatively. Apart from paracetamol, NSAIDs, voltaren and brufen were also taken by $12(22.6 \%)$ patients and $3(5.7 \%)$ 
patients respectively. Antibiotics were received by 44 patients (83\%). Augmentin was taken by 19 (35.8\%), amoxicillin by 14 (26.4\%), cefuroxime by $9(17 \%)$ and erythromycin by 2 (3.8\%) patients.

None of the patients that were admitted for surgery had fever preoperatively while $3(5.7 \%)$ of these patients reported with post-operative fever. All these 3 patients had normal WBC count before surgery and only 1 of these 3 patients had mild neutrophilia, while after surgery 2 of these cases showed raised WBC count and all of the 3 cases showed neutrophilia in their blood picture.

In current study, 11 (20.8\%) patients had WBC count above 11,000 per cubic millimeter post-operatively. Six out of these 11 cases showed neutrophils to be more than 70\%. Similarly, 10 (18.9\%) cases showed neutrophils to be more than $70 \%$ of which 6 cases showed WBC count above 11,000 per cubic millimeter. Ten (18.9\%) patients showed lymphocytes more than $40 \%$ of total WBC count. Three (5.7\%) cases had monocytes above $10 \%$ of the total WBC count. 2 cases (3.8\%) had eosinophils more than $6 \%$. Basophils were found to be within normal limits in all cases. The mean WBC count increased from 8200 to 9500 per cubic millimeter and the mean neutrophil percentage increased from $51.8 \%$ to $59.9 \%$ after the surgery. The differential percentages of other white blood cells decreased postoperatively to a slight extent.

Rate of infection (as indicated by WBC count more than $11,000 / \mathrm{mm}^{3}$ ) was $33.3 \%$ among those who did not develop secondary hemorrhage and it was $34.9 \%$ among those who developed secondary hemorrhage as shown in Table 1. Statistically it was not significant ( $\mathrm{p}=0.957)$.

Table 1: Association between infection and secondary hemorrhage.

\begin{tabular}{|c|c|c|c|c|}
\hline Secondary & \multicolumn{2}{|c|}{ Infection* } & & Total \\
\hline Hemorrhage & \multicolumn{2}{|c|}{ No } & Yes & \\
\hline No & 2 & $(66.7 \%)$ & $1(33.3 \%)$ & 3 \\
\hline Yes & 28 & $(65.1 \%)$ & $15(34.9 \%)$ & 43 \\
\hline Total & 30 & & 16 & 46 \\
\hline
\end{tabular}

Table 2: Association between antibiotics and secondary hemorrhage.

\begin{tabular}{|c|c|c|c|}
\hline \multirow{2}{*}{ Antibiotics } & \multicolumn{2}{|c|}{ Secondary Hemorrhage } & \multirow{2}{*}{ Total } \\
\cline { 2 - 3 } & No & Yes & \\
\hline None & $1(11.1 \%)$ & $8(88.9 \%)$ & 9 \\
\hline Amoxicillin & $0(0 \%)$ & $14(100 \%)$ & 14 \\
\hline Augmentin & $3(15.8 \%)$ & $16(84.2 \%)$ & 19 \\
\hline Cefuroxime & $1(11.1 \%)$ & $8(88.9 \%)$ & 9 \\
\hline Erythromycin & $1(50 \%)$ & $1(50 \%)$ & 2 \\
\hline Total & $6(11.3 \%)$ & $47(88.7 \%)$ & 53 \\
\hline
\end{tabular}

When the observation of secondary hemorrhage was crosstabulated against the intra-operative antibiotics used, it was found to have no significance $(\mathrm{p}=0.210)$ as shown in Table 2, Figures 1 \& 2 .
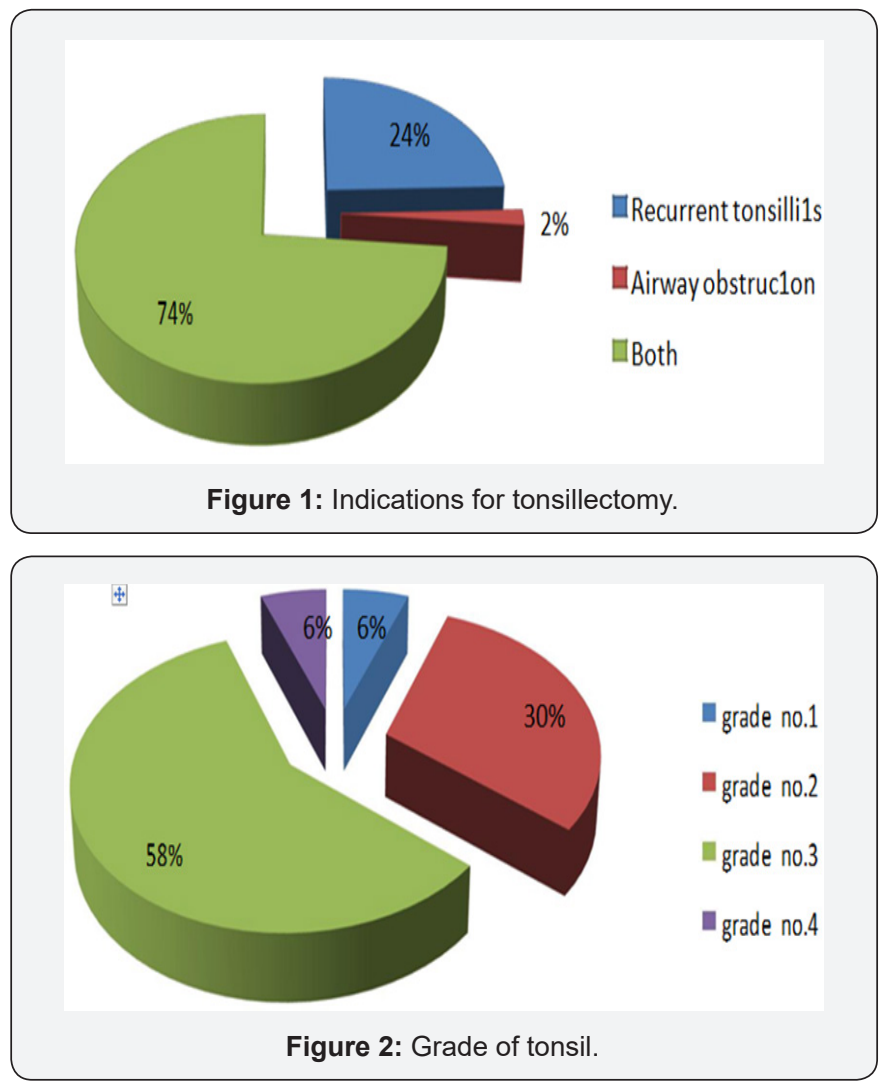

\section{Discussion}

Whether prophylactic antibiotics reduce the posttonsillectomy secondary haemorrhage? Although this question has been reviewed many a times by the most reputed investigators from Otolaryngology and repeatedly published in the ENT section of Cochrane Database of Systemic Reviews yet it remains unanswered [20]. After tonsillectomy, oral flora colonize in an open tonsillar fossa and may cause severe local inflammatory reaction through the action of chemical mediators such as lactic acid, leukotrines and prostaglandins resulting in post-operative pain and possibly haemorrhage [21]. The use of antibiotics post tonsillectomy has been advocated to quantitatively reduce the bacterial counts in the tonsillar fossa and thought to be associated with reduction of post-tonsillectomy pain and bleeding [19].

In relation to tonsillectomy, the hemorrhage risks vary between $1.5 \% 7$ and $40.0 \%$ [11]. Blakley [12] analyzed 63 reports on post-tonsillectomy hemorrhage and described a mean hemorrhage rate of $4.5 \%$ with a standard deviation of $9.4 \%$. He suggested a maximum expected hemorrhage rate of $13.9 \%$. The largest study on post-tonsillectomy hemorrhage was the prospective National Tonsil Audit in the UK carried out by Lowe et al. [13] in 2007 and covering about 34,000 patients undergoing tonsillectomy. They reported a postoperative hemorrhage rate 
of $3.5 \%$ covering bleeding that occurs during hospitalization and bleeding leading to re-admission; $0.9 \%$ of all patients were returned to theatre. Using data from the same study, van der Meulen et al. [6] found that postoperative hemorrhage after tonsillectomy with bipolar methods or coblation is three times higher compared to cold steel tonsillectomy alone. $84 \mathrm{~A}$ retrospective study by Windfuhr et al. [14] conducted on 15,218 patients in Germany in 2005 found a return-to-theatre rate of $2.86 \%$ for tonsillectomy and $0.25 \%$ for adenoidectomy. A metaanalysis by Krishna and Lee reported a haemorrhage rate of $3.3 \%$ after tonsillectomy for patients with normal coagulation tests [15].

The risk factors associated with post tonsillectomy hemorrhage range from type of surgery, the patients' age and sex, indication for surgery, operation technique, and abnormal coagulation tests to postoperative infection of the tonsillar fossa. A study from 2007 showed that postoperative infection of the tonsillar fossa is no risk factor for secondary hemorrhage [16] while another study described a positive relationship between preoperative bacterial colonization of the tonsillar fossa and postoperative hemorrhage, recommending antibiotics [17]. However, prescribed antibiotics did not reduce the risk of posttonsillectomy hemorrhage in general $[18,19]$.

The rate of post-tonsillectomy secondary haemorrhage found in our study is much higher than the published rate of 9.5\% by Ahsan et al. from United Kingdom [16]. Almomani and Al-husban from Jordan also reported low incidence of post-tonsillectomy secondary bleeding and also found that prophylactic use of antibiotics like Amoxicillin with Clavulanic acid and oral panicillins had no significant reduction of bleeding as compared to placebo [21]. However, the incidence of bleeding was far less in Amoxicillin with Clavulanic acid group as compared to oral panicillins and placebo group but this finding was not sufficiently highlighted during the statistical analysis of observations by the authors.

Similarly, the most recent Cochrane Review concludes that although individual studies included in meta-analysisvary in their findings, there is no evidence to support that usage of antibiotics decrease morbidity rates post tonsillectomy (i.e secondary heamorrahage and pain) yet a limited benefit with antibiotics was noticed which lead to the further queries. More important, existence of a subgroup who might benefit from administration of antibiotics in unknown and needs more investigation in future [22]. Such limited role of antibiotics in reducing post-tonsillectomy secondary bleeding is also documented by others elsewhere [23].

In current study, $11(20.8 \%)$ patients had WBC count above 11,000 per cubic millimeter post-operatively. Six out of these 11 cases showed neutrophils to be more than $70 \%$. Similarly, 10 (18.9\%) cases showed neutrophils to be more than $70 \%$ of which 6 cases showed WBC count above 11,000 per cubic millimeter. Ten $(18.9 \%)$ patients showed lymphocytes more than $40 \%$ of total WBC count. Three (5.7\%) cases had monocytes above $10 \%$ of the total WBC count. These findings were in agreement with the observations reported by previous investigators [24-26].

In current study, it was seen that none of the patients who received Amoxicillin could be prevented from developing a secondary bleeding after tonsillectomy whereas $15.8 \%$ of the patients who received Augmentin did not develop secondary haemorrhage. But these apparent differences were not large enough to build a statistically significant conclusion. Secondly, the small sample size was a big limitation of this study. Dhiwakar et al. [18,19] also reported the same fact. Ahsan et al. [27] also documented similar observations but suggested substantial role of infection in the aetiopathogenesis of post-tonsillectomy secondary bleeding which triggered a lot of criticism subsequently [17,28-31].

In the summary, authors suggest that the exact mechanism of infectious process in the post-tonsillectomy secondary haemorrhage and effectiveness of antibiotics in reducing this common complication of the routine ENT procedure is a controversial and poorly understood topic. Although majority of clinical trials reviewed by the authors and by the Cochrane Reviews mentioned above do not suggest any important role of antibiotics yet a few reports stating their role cannot be defied unless a few large multicenter randomized controlled trials are undertaken to accept or rejection the notion.

\section{Conclusion}

Current study concludes that infection is not a significant cause of post-tonsillectomy secondary hemorrhage and use of antibiotics has no role in reduction of such hemorrhage.

\section{References}

1. Blair RL, McKerrow WS, Carter NW, Fenton A (1996) The Scottish tonsillectomy audit. Audit Sub-Committee of the Scottish Otolaryngological Society. J Laryngol Otol 20: 1-25.

2. Kumar R (1984) Secondary haemorrhage following tonsillectomy/ adenoidectomy. J Laryngol Otol 98(10): 997-998.

3. Lee MSW, Montague ML, Hussain SSM (2003) The admission of patients with peri-tonsillar abscess to a general ENT ward and its influence on secondary post-tonsillectomy haemorrhage. Clin Otolaryngol Allied Sci 28(1): 48-50.

4. Windfuhr J, Seehafer M (2001) Classification of haemorrhage following tonsillectomy. J Laryngol Otol 115(6): 457-461.

5. Faulconbridge RV, Fowler S, Horrocks J, Topham JH (2000) Comparative audit of tonsillectomy. Clin Otolaryngol Allied Sci 25(2): 110-117.

6. Lowe D, van der Meulen J (2004) Tonsillectomy technique as a risk factor for postoperative haemorrhage. Lancet 364(9435): 697- 702.

7. Carmody D, Vamadevan T, Cooper SM (1982) Post tonsillectomy haemorrhage. J Laryngol Otol 96(7): 635-638.

8. Fox SL, West GB (1948) Bleeding following tonsillectomy and adenoidectomy. Ann Otol Rhinol Laryngol 57(4): 1032-1040.

9. James AG (1948) Hemorrhages following tonsillectomy and adenoidectomy related to weather during a 12-year period. Ann West Med Surg 2(12): 558-561. 
10. Walner DL, Karas A (2013) Standardization of reporting posttonsillectomy bleeding. Ann Otol Rhinol Laryngol 122(4): 277-282.

11. Evans AS, Khan AM, Young D, Adamson R (2003) Assessment of secondary haemorrhage rates following adult tonsillectomy--a telephone survey and literature review. Clin Otolaryngol Allied Sci 28(6): 489-491.

12. Blakley BW (2009) Post-tonsillectomy bleeding: how much is too much? Otolaryngol Head Neck Surg 140(3): 288-290.

13. Lowe D, van der Meulen J, Cromwell D, Lewsey J, Copley L, et al (2007) Key messages from the National Prospective Tonsillectomy Audit. Laryngoscope 117(4): 717-724.

14. Windfuhr JP, Chen YS, Remmert S (2005) Hemorrhage following tonsillectomy and adenoidectomy in 15,218 patients. Otolaryngol Head Neck Surg 132(2): 281-286

15. Krishna P, Lee D (2001) Post-tonsillectomy bleeding: a meta-analysis. Laryngoscope 111(8): 1358-1361.

16. Ahsan F, Rashid H, Eng C, Bennett DM, Ah-See KW (2007) Is secondary haemorrhage after tonsillectomy in adults an infective condition? Objective measures of infection in a prospective cohort. Clin Otolaryngol 32(1): 24-27.

17. Lowe D, Moumoulidis I, George A (2007) Re: is secondary haemorrhage after tonsillectomy in adults an infective condition? Clin Otolaryngol 32(4): 306-307.

18. Dhiwakar M, Eng CY, Selvaraj S, McKerrow WS (2006) Antibiotics to improve recovery following tonsillectomy: a systematic review. Otolaryngol Head Neck Surg 134(3): 357-364.

19. Dhiwakar M, Clement WA, Supriya M, McKerrow W (2010) Antibiotics to reduce post-tonsillectomy morbidity. Cochrane Database Syst Rev 7: CD005607.

20. Browning GG (2010) Prophylactic steroids and/or antibiotics to reduce post-tonsillectomy morbidity: a yet unanswered conundrum. Clin Otolaryngol 35(5): 417.
21. Almomani OS, Al-husban H (2010) Using Antibiotics Post Tonsillectomy. Middle East Journal of Family Medicine 8(3): 7-9.

22. Dhiwakar M, Clement WA, Supriya M, McKerrow W (2012) Antibiotics to reduce post-tonsillectomy morbidity. Cochrane Database Syst Rev 12: CD005607.

23. Limited role for antibiotics post-tonsillectomy. New Zealand Doctor 2008:21.

24. Karaman M, Tek A, Tuncel A, Oysu C, Sheidaei S (2012) Adult tonsillectomy: relationship between indications and postoperative hemorrhage. Kulak Burun Bogaz Ihtis Derg 22(1): 21-25.

25. Liu DB, Tan ZY, Zhong JW, Shao JB, Qiu SY, et al. (2010) A preliminary study of the secondary postoperative haemorrhage in pediatric coblation adenotonsillectomy. Zhonghua Er Bi Yan Hou Tou Jing Wai Ke Za Zhi 45(5): 373-376.

26. Ovesen T, Kamarauskas G, Dahl M, Mainz J (2012) Pain and bleeding are the main determinants of unscheduled contacts after outpatient tonsillectomy. Dan Med J 59(2): A4382.

27. Dhiwakar M, Clement WA, Supriya M, McKerrow WS (2008) Antibiotics to reduce post-tonsillectomy morbidity. Cochrane Database Syst Rev (2): CD005607.

28. Cherry JR (2007) Re: is secondary haemorrhage after tonsillectomy in adults an infective condition? Objective measures of infection in a prospective cohort. Clin Otolaryngol 32(4): 303.

29. Flook E (2007) Re: is secondary haemorrhage after tonsillectomy in adults an infective condition? Clin Otolaryngol 32(4): 308-309.

30. Leong AC (2007) Re: is secondary haemorrhage after tonsillectomy in adults an infective condition? Clin Otolaryngol 32(4): 303-304.

31. O'Donnell S, Shayah A, Makura ZG (2007) Re: is secondary haemorrhage after tonsillectomy in adults an infective condition? Clin Otolaryngol 32(4): 307-308.

\section{Your next submission with Juniper Publishers} will reach you the below assets

- Quality Editorial service

- Swift Peer Review

- Reprints availability

- E-prints Service

- Manuscript Podcast for convenient understanding

- Global attainment for your research

- Manuscript accessibility in different formats

( Pdf, E-pub, Full Text, Audio)

- Unceasing customer service

Track the below URL for one-step submission https://juniperpublishers.com/online-submission.php 